\title{
Increase in blood pressure over a 7-year period in a mixed-ancestry South African population
}

\author{
S F G Davids, ${ }^{1,2}$ MSc; T E Matsha, ${ }^{2} \mathrm{PhD} ; \mathbf{N}$ Peer, ${ }^{1,3} \mathrm{MB}$ ChB, MBA, PhD; R T Erasmus, ${ }^{4}$ MMed (Chem Path); A P Kengne, ${ }^{1,3} \mathrm{MD}, \mathrm{PhD}$ \\ ${ }^{1}$ Department of Medicine, Faculty of Health Sciences, University of Cape Town, South Africa \\ ${ }^{2}$ South African Medical Research Council/Cape Peninsula University of Technology Cardiometabolic Health Research Unit, Department of \\ Biomedical Sciences, Faculty of Health and Wellness Sciences, Cape Peninsula University of Technology, Cape Town, South Africa \\ ${ }^{3}$ Non-Communicable Diseases Research Unit, South African Medical Research Council, Cape Town, South Africa \\ ${ }^{4}$ Department of Chemical Pathology, National Health Laboratory Service and Faculty of Medicine and Health Sciences, Stellenbosch University, \\ Cape Town, South Africa
}

Corresponding author: S F G Davids (davidss@cput.ac.za)

\begin{abstract}
Background. An increase in the prevalence of high blood pressure (BP) has been reported globally and in the South African (SA) population. Objectives. To investigate temporal changes in absolute BP levels and hypertension prevalence in the mixed-ancestry South Africans. Methods. Participants were from two independent cross-sectional surveys conducted during 2008/09 (N=928) and 2014/16 (N=1 969) in Bellville South, Cape Town, SA. Participants' eligibility was based on several criteria, including age $>20$ years and neither bedridden nor pregnant. Data were obtained by administered questionnaires, clinical measurements (BP and anthropometry) and biochemical assessments (oral glucose tolerance tests and cotinine levels). Known hypertension was based on a self-reported history of doctor-diagnosed hypertension and ongoing treatment. Comparison across years was based on the crude prevalence of hypertension as well as direct agestandardised prevalence, based on the SA 2011 mixed-ancestry population distribution, in 10-year age increments.

Results. In all, 708 participants (76.3\%) in 2008/09 and 1488 (75.6\%) in 2014/16 were female. Between 2008/09 and 2014/16, mean systolic BP increased from 124 to $136 \mathrm{mmHg}$ (absolute mean difference $15 \mathrm{mmHg}$ ) and mean diastolic BP from 75 to $85 \mathrm{mmHg}$ (absolute mean difference $9 \mathrm{mmHg}$ ) in the overall sample. The prevalence of screen-detected hypertension increased from $11.6 \%$ to $24.8 \%$, with a similar increase in males and females, while the prevalence of known cases remained stable. These changes remained significant after adjustment for age and gender.

Conclusions. A rightward shift in absolute BP translated into a significant increase in the prevalence of hypertension over time in this population. The predominant increases in screen-detected hypertension suggest that the deteriorating profile was not matched by efforts to detect and manage individuals with higher-than-optimal BP levels.
\end{abstract}

S Afr Med J 2019;109(7):503-510. DOI:10.7196/SAMJ.2019.v109i7.13663

Hypertension is the most prevalent non-communicable disease (NCD) risk factor, estimated to affect two in five adults globally and responsible for $\sim 9.4$ million deaths each year. ${ }^{[1]}$ The highest prevalence of hypertension, at $46 \%$, is in the World Health Organization (WHO)'s African Region, where it is frequently undiagnosed. ${ }^{[1,2]}$ Undiagnosed hypertension is of concern because of the serious complications associated with raised blood pressure (BP). These include cardiovascular diseases such as strokes and heart attacks, kidney failure, cognitive impairment and blindness. ${ }^{[3,4]}$

The prevalence of hypertension in South Africa (SA) is high, similar to rates reported on the rest of the continent. In the 2016 South African Demographic and Health Survey (SADHS) ${ }^{[5]}$ the prevalence was $46 \%$ and $44 \%$ in $\geq 15$-year-old females and males, respectively. These figures represent a high and rising burden of hypertension in the country, the prevalence having increased 1.8 . 2 -fold by $2016^{[5]}$ compared with 1998 , when it was $25 \%$ in females and $23 \%$ in males. ${ }^{[6]}$ The prevalence of hypertension in national surveys generally reflects findings in black Africans, who comprise the majority of SA's population $(80.8 \%) .{ }^{[7]}$ The other historically defined SA population groups include white (8.0\%), Indian/Asian (2.5\%) and coloured or mixed-ancestry individuals $(8.8 \%)$; the latter have Khoisan, white, black and Malay heritage. ${ }^{[7]}$ In the 2016 SADHS, ${ }^{[5]}$ mixed-ancestry females and males had a much higher prevalence of hypertension ( $57 \%$ and $58 \%$, respectively) than their black
African counterparts (females $44 \%$, males $41 \%$ ). The prevalence of hypertension in the mixed-ancestry population was 1.9-fold and 2.2fold higher in 2016 compared with 1998, when it was $30 \%$ in females and $26 \%$ in males. ${ }^{[5,6]}$

\section{Objectives}

The above findings, from a national study, are not generalisable to specific communities in SA because of urban-rural, provincial, population group and other differences. These data should therefore not be used to estimate the hypertension prevalence and patterns in the mixed-ancestry population of Cape Town, for which there is a dearth of recent information. Determining accurate hypertension prevalence and patterns at a local level is necessary to allocate healthcare resources optimally and appropriately and develop costeffective therapeutic strategies and programmes for that community.

The objective of this study was therefore to investigate the temporal changes in absolute BP levels and hypertension prevalence from $2008 / 09$ to $2014 / 16$ in the mixed-ancestry population of Bellville South, a suburb of Cape Town, Western Cape Province, SA.

\section{Methods}

Study population and sampling procedure

The present study was a comparison of two independent crosssectional studies conducted in 2008/09 and 2014/16 in the 
predominantly mixed-ancestry population of Bellville South. The mixed-ancestry population, also known as coloured, has $32-43 \%$ Khoisan (indigenous South Africans), 20 - 36\% Bantu-speaking African, 21 - 28\% European and 9 - 11\% Asian ancestry and is unique to SA. ${ }^{[8]}$ Bellville South township (i.e. underdeveloped urban area) is located in the northern suburbs of Cape Town and was founded in the late 1950s. The initial study was conducted in $\geq 18$-year-old residents and the second study in $\geq 20$-year-olds, using randomised street selection. Trained fieldworkers approached every dwelling in the selected streets and invited all potential individuals from each household who fulfilled the inclusion criteria to participate. If there was no answer, the recruiters would make a note and then move to the next house, making it difficult to determine the number of nonresponders in both studies. During the 2008/09 survey, 946 subjects were recruited, as previously described by Zemlin et al. ${ }^{[9]}$ and during the 2014/16 survey an additional 1989 subjects were recruited. Consenting individuals living in Bellville South, of mixed ancestry, $\geq 20$ years of age and neither bedridden nor pregnant, were included.

\section{Ethics approval and consent to participate}

Ethics approval for the 2008/09 and 2014/16 studies was obtained from the Cape Peninsula University of Technology (ref. nos CPUT/ HW-REC 2008/002 and CPUT/HW-REC 2015/H01, respectively), while ethics approval for the present study was obtained from the University of Cape Town Human Research Ethics Committee (ref. no. 442/2016). Permission to conduct the analysis was granted by the City of Cape Town and community management. All participants had provided written informed consent.

\section{Data collection}

Trained research personnel administered questionnaires and collected clinical and biochemical measurements at a designated research site. Anthropometric measurements, including weight, height, and hip and waist circumferences, were obtained using standardised techniques as prescribed by the WHO. ${ }^{[10]}$ Each measurement was taken three times and then averaged. Registered nurses measured the participants' BPs, using electronic BP monitors; BP readings were taken three times at 3 -minute intervals, ${ }^{[10]}$ and the lowest systolic $\mathrm{BP}$ (SBP) and corresponding diastolic $\mathrm{BP}$ (DBP) readings were used. Participants with no history of clinically diagnosed diabetes mellitus underwent a $75 \mathrm{~g}$ oral glucose tolerance test (OGTT) as recommended by the WHO. ${ }^{[11]}$

\section{Definitions}

Level of education was categorised into two groups, namely $\leq 7$ years of education (completion of primary school) and $>7$ years (secondary schooling and higher). Body mass index (BMI, $\mathrm{kg} / \mathrm{m}^{2}$ ) was defined as normal weight $\left(<25.0 \mathrm{~kg} / \mathrm{m}^{2}\right)$, overweight $\left(25.0-29.99 \mathrm{~kg} / \mathrm{m}^{2}\right)$ and obese $\left(\geq 30.0 \mathrm{~kg} / \mathrm{m}^{2}\right)$. Known hypertension was defined as individuals who were diagnosed as hypertensive and currently on medication, and screen-detected hypertension as BP $\geq 140 / 90 \mathrm{mmHg}$. Diabetes was defined as a fasting plasma glucose level $\geq 7.0 \mathrm{mmol} / \mathrm{L}$ and/or a 2-hour post-OGTT plasma glucose level $\geq 11.1 \mathrm{mmol} / \mathrm{L}$, or selfreported on diabetes medication. Prediabetes was defined as a fasting plasma glucose level between $6.1 \mathrm{mmol} / \mathrm{L}$ and $6.9 \mathrm{mmol} / \mathrm{L}$ and/or a post 2-hour glucose level between $7.8 \mathrm{mmol} / \mathrm{L}$ and $11.1 \mathrm{mmol} / \mathrm{L}^{[11]}$ Current tobacco use was defined as a cotinine level $>10 \mathrm{ng} / \mathrm{mL}^{[12,13]}$ Alcohol consumption was self-reported.

\section{Statistical analysis}

The software programmes Statistica version 13 (Dell, USA) and SPSS version 24 (IBM, USA) were used for data analysis. The results are reported as means, standard deviations (SDs), percentages and confidence intervals (CIs). Student's $t$-test was used to assess the significance of absolute differences in mean BP over time, while the $\chi^{2}$ test was used for categorical variables. The crude prevalence of hypertension as well as the direct age-standardised prevalence, based on the SA 2011 mixed-ancestry population distribution, were estimated in 10-year age increments. ${ }^{[14]}$ Multivariable linear regression, adjusted for age, gender and years of study, assessed the effects of BMI, waist circumference, diabetes status, tobacco and alcohol use, and level of education on absolute BP levels. Equivalent logistic regression models, adjusted for age, gender and year of study, investigated the predictors of hypertension overall (known and screen detected) and separately for screen-detected hypertension. A $p$-value $<0.05$ characterised statistically significant results.

\section{Results}

The final sample size for the 2008/09 survey was 928 after excluding participants aged $<20$ years, 5 non-consenting individuals and a single participant who withdrew from the study. The final sample size for the 2014/16 survey was 1969 after excluding 10 participants who were not eligible and 10 who withdrew from the study.

Differences between participants in 2008/09 and 2014/16 The majority of participants in both studies were female (2008/09: 76.3\%, $n=708$, and 2014/16: 75.6\%, $n=1$ 488) (Table 1). In 2014/16, participants were younger than in the 2008/09 study (mean age: overall 49.6 v. 54.3 years, respectively, females 50.3 v. 53.7 years, and males 47.4 v. 56.3 years; all $p<0.001$ ). The level of education was similar across both surveys (all $p>0.612$ ), with about two-thirds of participants having completed $>7$ years of education.

Within the surveys, male v. female differences were observed for some characteristics, but not consistently across the two surveys, specifically with regard to males being younger in 2014/16 compared with 2008/09 (Table 1). This translated across anthropometric and behavioural findings for males, with weight, BMI, waist and hip measurements and diabetes status being lower in 2014/16 compared with 2008/09. Furthermore, although the overall BMI decreased marginally between 2008/09 and 2014/16 (mean (SD) 29.9 (7.3) v. $\left.29.2(8.0) \mathrm{kg} / \mathrm{m}^{2}\right)$, with a non-significant decrease in females $(31.0$ v. $\left.30.7 \mathrm{~kg} / \mathrm{m}^{2} ; p=0.349\right)$, BMI decreased significantly in males $(26.1$ v. $\left.24.6 \mathrm{~kg} / \mathrm{m}^{2} ; p=0.003\right)$. In $2008 / 09$ and $2014 / 16$, the percentage of current alcohol users was similar overall $(27.3 \%$ v. $26.6 \%)$ and in females $(21.2 \%$ v. $22.3 \%)$, but decreased in males $(47.0 \%$ v. $39.5 \%$; $p<0.001)$. The proportion of current smokers increased in all groups over the 7 -year period: $42.5 \%$ v. $49.8 \%$ overall, $40.9 \%$ v. $46.2 \%$ in females, and $47.7 \%$ v. $60.8 \%$ in males (all $p<0.019$ ).

\section{Differences in BP and hypertension between 2008/09 and 2014/16}

Mean BP levels increased between 2008/09 and 2014/16 from $124 \mathrm{mmHg}$ to $136 \mathrm{mmHg}$ for SBP and from $75 \mathrm{mmHg}$ to $85 \mathrm{mmHg}$ for DBP in the overall sample (both $p<0.001$ ). A similar pattern was observed for males and females (Figs 1 and 2). Between 2008/09 and 2014/16, the greatest increases for SBP were $19 \mathrm{mmHg}$ in females and $13 \mathrm{mmHg}$ in males, while for DBP these were $12 \mathrm{mmHg}$ and $9 \mathrm{mmHg}$ in males and females, respectively (Fig. 1).

The crude and age-standardised hypertension prevalence increased from $48.4 \%$ and $30.7 \%$, respectively, in $2008 / 09$ to $59.1 \%$ and $45.0 \%$ in $2014 / 16(p<0.001)$. Of concern was the high proportion of screendetected or unknown hypertension, which more than doubled between 2008/09 and 2014/16; the crude prevalence increased from $11.6 \%$ to $24.8 \%$ and the age-standardised prevalence from $8.3 \%$ 


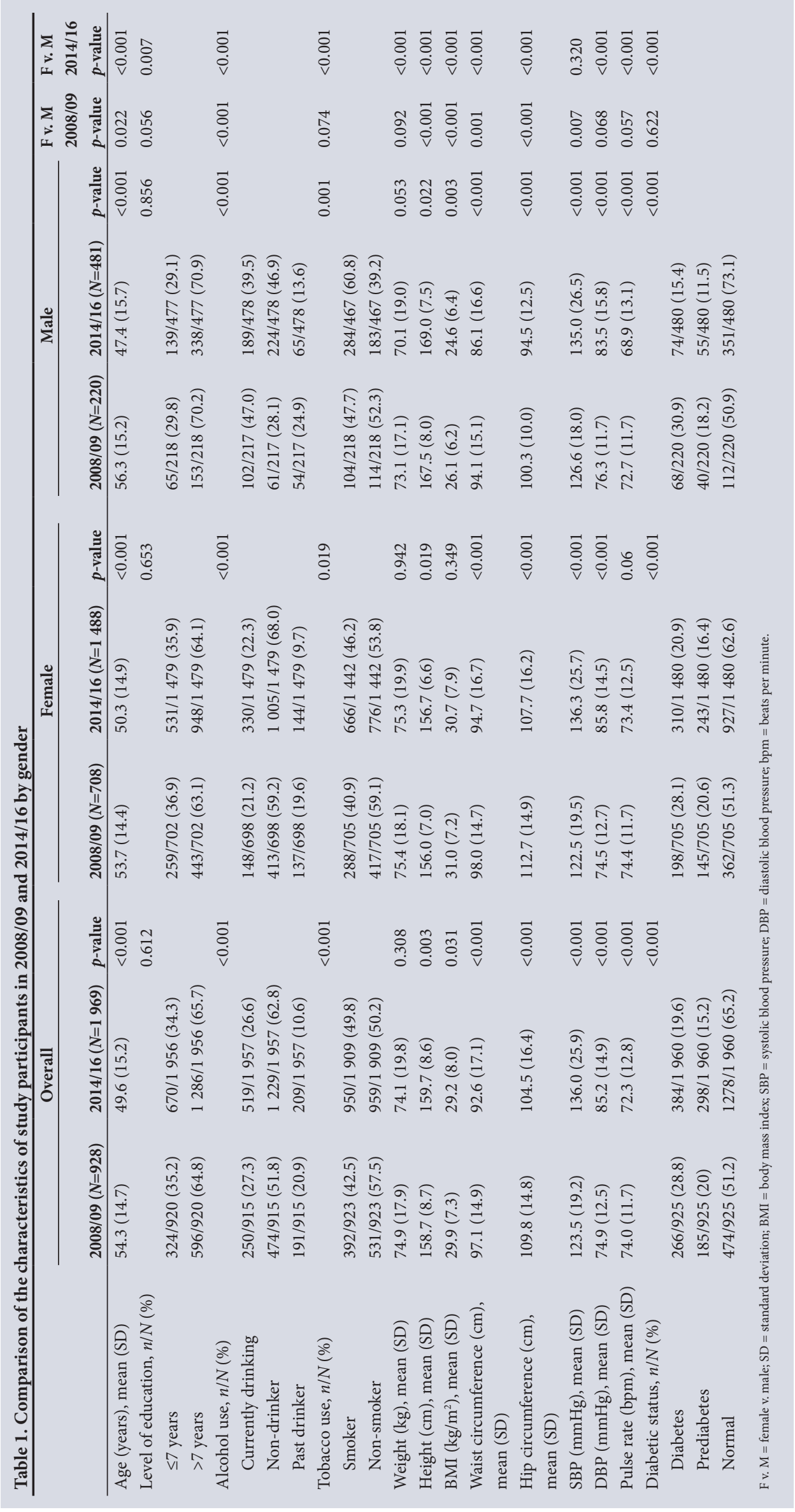

to $22.9 \%$ (both $p \leq 0.003$ ). Crude screen-detected hypertension by gender increased in both females $(11.0 \%$ to $23.7 \% ; p<0.001)$ and males ( $13.6 \%$ to $28.3 \%$; $p<0.001$ ).

In contrast, the prevalence of known hypertension in the overall sample mostly remained stable: $36.7 \%$ in 2008/09 v. $34.3 \%$ in $2014 / 16$ for crude prevalence, and $22.4 \%$ v. $22.1 \%$ for age-standardised prevalence. However, this concealed a significant decrease in known hypertension prevalence for males from $34.5 \%$ to $22.7 \%$ ( $p=0.013$ ); there was minimal change for females $(37.4 \%$ v. $38.1 \%$; $p=0.838$ ) (Table 2). There was evidence of interaction by gender in the change of hypertension prevalence across years (known hypertension: $p=0.030$ for gender ${ }^{\star}$ year and screen-detected hypertension: $p<0.001$ for gender ${ }^{*}$ year; Table 2).

Furthermore, when comparing the relationship between age and hypertension prevalence, there was a highly significant decrease in the mean (SD) age of participants with screen-detected hypertension from 58.6 (14.5) years in $2008 / 09$ to 51.0 (13.8) years in 2014/16 ( $p<0.001)$. Although the prevalence of screen-detected hypertension increased with age in 2008/09, peaking in the oldest age group (17.8\%), in 2014/16 it peaked in the $40-49$-year age group (31.9\%) (Fig. 3).

\section{Determinants of changes in $\mathrm{BP}$ and hypertension}

In linear regression models, data from the two surveys were combined and adjusted for age, gender and year of study. Compared with $2008 / 09$, the participants in 2014/16 had $15.6 \mathrm{mmHg}$ (95\% CI 13.9 - 17.4) higher SBP and $11.1 \mathrm{mmHg} \quad(95 \%$ CI 10.0 12.2) higher DBP. Furthermore, age, BMI, waist circumference, diabetes, prediabetes, current smoking and current alcohol use were associated with both SBP and DBP, while higher education level was inversely associated with SBP (Table 3).

In an expanded multivariable model using a backward selection method of the above variables, 


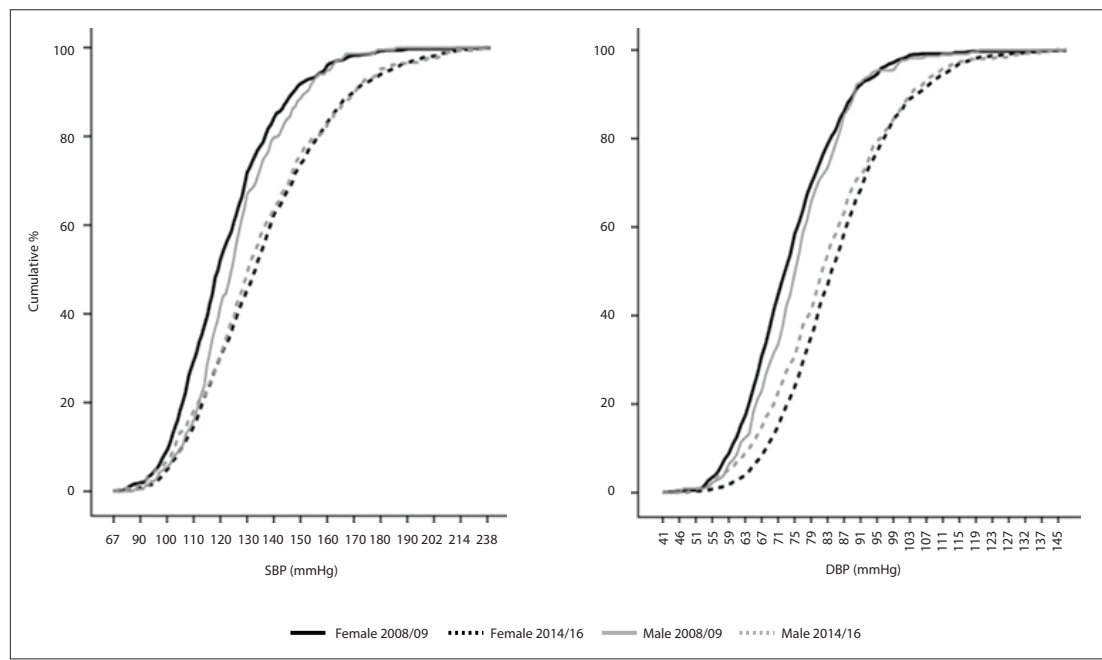

Fig. 1. Cumulative distribution of overall hypertension status (normal, known hypertension and screendetected hypertension) by SBP and DBP for 2008/09 and 2014/16. (SBP = systolic blood pressure; $D B P=$ diastolic blood pressure.)

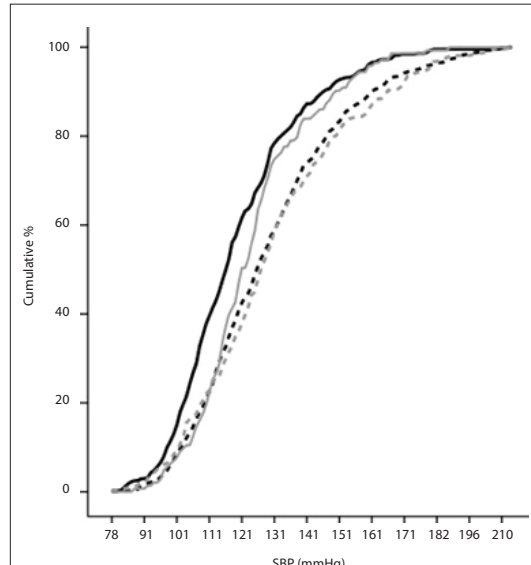

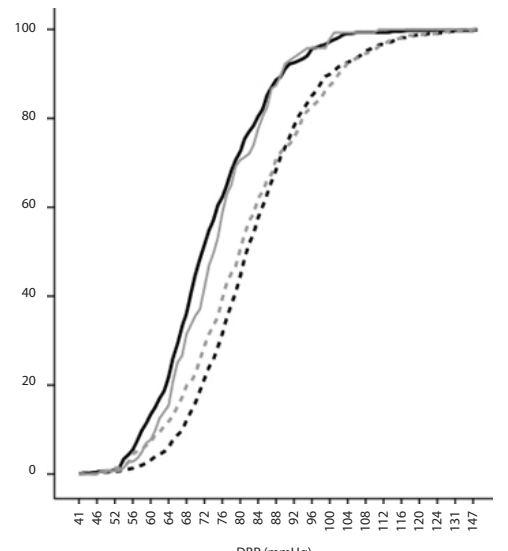

$\mathrm{DBP}(\mathrm{mmHg})$
— Female 2008/09 ....... Female 2014/16 — Male 2008/09 $\quad$........ Male 2014/16

Fig. 2. Cumulative distribution of screen-detected hypertension by SBP and DBP for 2008/09 and 2014/16. (SBP = systolic blood pressure; DBP = diastolic blood pressure. $)$

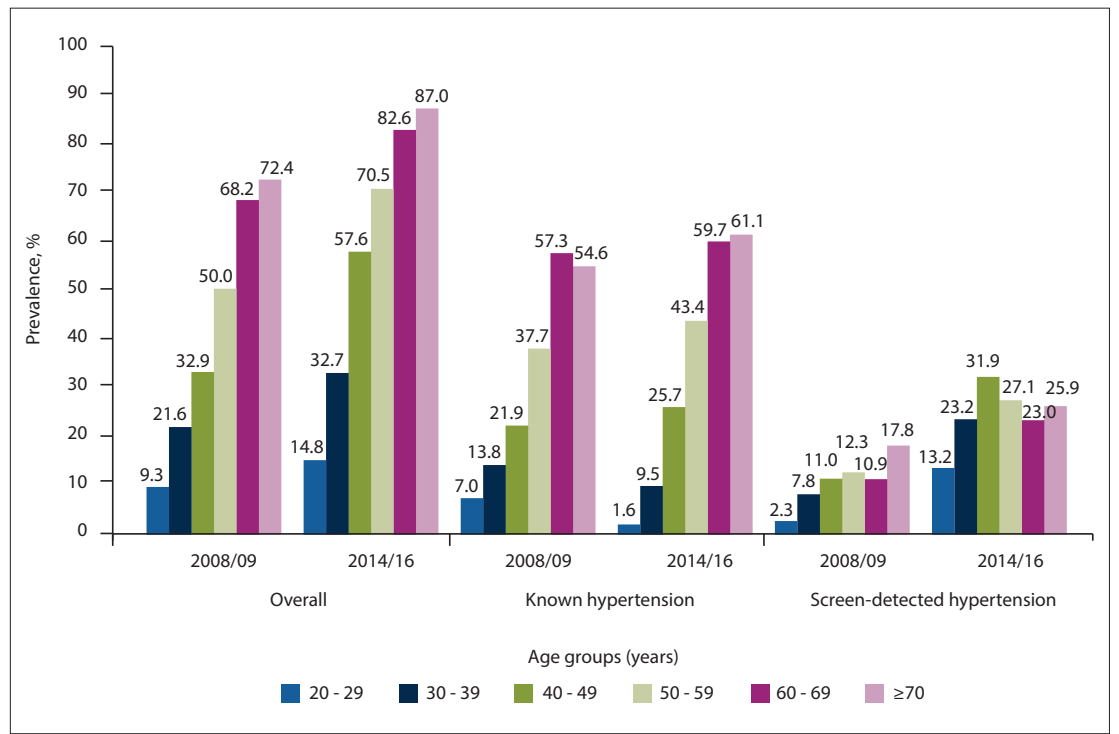

Fig. 3. Comparison of the prevalence of hypertension (overall, known and screen detected) between 2008/09 and 2014/16 by age group. age, BMI, abnormal glucose tolerance and current drinking were associated with both SBP and DBP, while higher education level was inversely associated with SBP (Table 4). Furthermore, the model showed that the study period, i.e. $2014 / 16$ as opposed to 2008/09, was associated with higher SBP (16.0 mmHg; 95\% CI 14.2 - 17.7), as well as higher DBP (11.5 mmHg; 95\% CI 10.7 12.9).

In logistic regression models adjusted for age, gender and year of study, participants in 2014/16 compared with 2008/09 had almost 3 -fold higher odds of hypertension (odds ratio (OR) 2.83, 95\% CI 2.33 - 3.45). The odds for screen-detected hypertension were 4-fold greater (OR 4.33, 95\% CI 3.29 - 5.69) (Table 5). Older age, current alcohol use, and overweight and obesity were associated with higher odds of hypertension and screen-detected hypertension (Table 5). Additionally, diabetes was significantly associated with hypertension, while lower education level was related to screendetected hypertension; the OR for the latter was lower for past drinking v. no drinking.

\section{Discussion}

\section{Increases in overall hypertension} prevalence over a 7 -year period

The present study showed a highly significant increase in overall hypertension prevalence in the mixed-ancestry population living in Cape Town. Results from two cross-sectional studies conducted in the same community (Bellville South) showed a 1.5-fold increase in age-standardised hypertension over a 7 -year period from 2008/09 (30.7\%) to 2014/16 (45.0\%). The rise in hypertension prevalence in this community over 7 years was similar to that reported by Peer et al.$^{[3]}$ for black Africans in Cape Town over an 18-year period (a 1.8-fold increase from 21.6\% to $38.9 \%) .{ }^{[3]}$ These increases may reflect differential contributors to hypertension in these communities, but probably represent an accelerated increase in hypertension risk factors over time. Peer et al. ${ }^{[3]}$ conducted their comparison between 1990 and 2008/09, while the present comparison was between 2008/09 and 2014/16. Rapid increases in urbanisation over the past decade and the associated growth of hypertension risk factors may be contributing to a steep nonlinear rise in hypertension in Cape Town.

\section{High prevalence of screen-detected hypertension}

The high prevalence of screen-detected hypertension (50\%) in 2014/16 and the almost 3-fold increase in screen-detected hypertension between 2008/09 and 


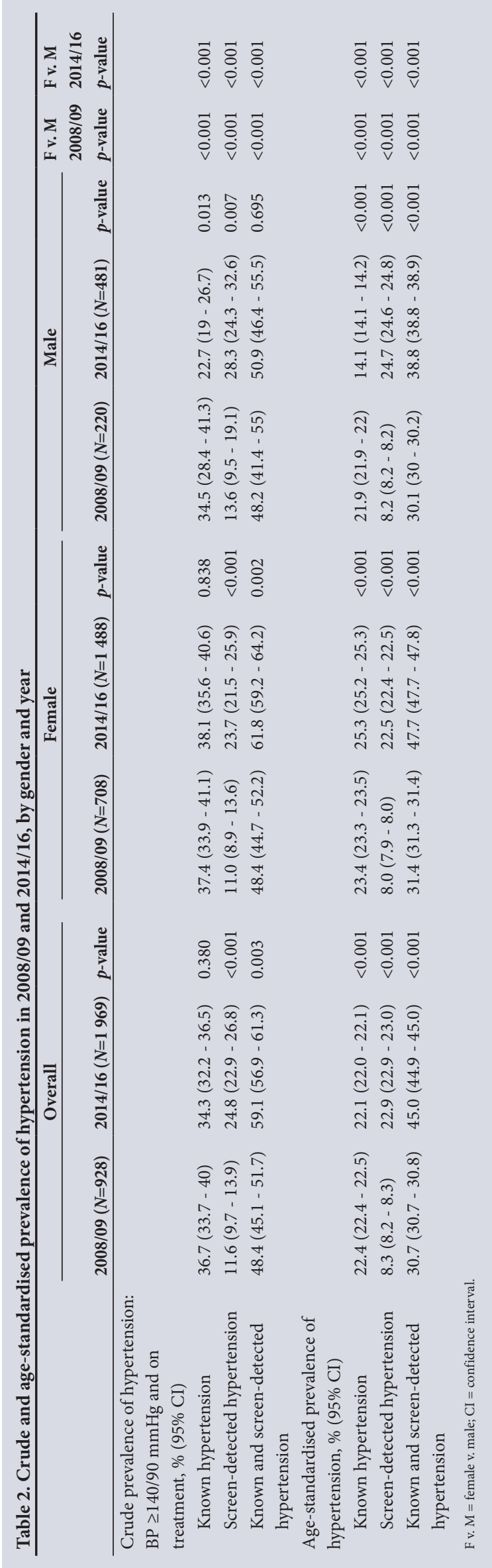

2014/16 are of concern, demonstrating failure of the healthcare system to provide adequate hypertension detection and treatment services in the mixed-ancestry population in Cape Town. Despite the high and rising prevalence of hypertension in this community, the stable prevalence of known hypertension indicates that minimal screening efforts are being undertaken. This situation is unacceptable in view of the severity of hypertension-related complications and the minimal costs involved, apart from time, in measuring BP. An increase in hypertension awareness in the community and a concerted drive by the healthcare sector to promote hypertension screening and to 'know your numbers' are required. These efforts need to be accompanied by an increase in healthcare resources such as staff and medication to optimally treat the high burden of screendetected hypertension.

The National Department of Health (NDoH) in SA prioritised the management of NCDs at the South African Summit on the Prevention and Control of NCDs in 2011. One of the goals was to reduce the prevalence of raised BP by $20 \%$ by $2020 .{ }^{[15]}$ However, the numerous good legislative and policy initiatives formulated by the $\mathrm{NDoH}$ for the control and management of hypertension over the past two decades have unfortunately not been translated into successful action, as demonstrated the findings of the present study.

Our results primarily reflect a significant increase in newly diagnosed cases of hypertension, with a stable known hypertension prevalence. Despite provision by the SA government of guidelines to increase awareness of NCDs, large numbers of individuals are unaware of their hypertensive status, clearly indicating that the hypertension epidemic exceeds efforts to detect, treat and control the disease and suggesting that hypertension, which has been called the 'silent killer' because symptoms are absent in the early stages, ${ }^{[16]}$ may need to be combated with tactics different to those that have been used so far. Although the government is implementing strategies to control NCDs, opportunistic screening at healthcare facilities is generally still relied on to diagnose hypertension, and difficulties in physical access to healthcare and low socioeconomic status are further major challenges in curbing NCD rates. Approximately two-thirds of the Western Cape population lives in the City of Cape Town, which results in overburdened public healthcare facilities with long queues and staff shortages ${ }^{[17,18]}$ Access to private healthcare is only available to those people who are able to afford the facilities or are on a medical aid. Our findings therefore suggest that further strategies are required to create awareness programmes and screening opportunities aimed at reducing or preventing further increases in NCDs, and that these must be accompanied by solutions to the causal effects of the increase in hypertension prevalence.

\section{Shift in peak prevalence from old age to middle age}

In contrast to the 2008/09 findings and global trends in general, ${ }^{[16]}$ in 2014/16 hypertension prevalence peaked at a much younger age. This was particularly true for screen-detected hypertension, where the prevalence peaked in 40 - 49-year-olds in 2014/16 as opposed to $\geq 70$-year-olds in 2008/09. The shift in peak hypertension prevalence by age was unexpected, and may be due to earlier, sustained and longer exposures to lifestyle-related risk factors than those experienced a decade ago. Hypertension is now affecting the younger working-age population in this community, who are in their prime; a decade ago, it was the older retired members of society who most commonly developed the disease. This change will have far-reaching social and financial effects, as the loss of breadwinners who succumb to uncontrolled hypertension and its complications drains household incomes and perpetuates the cycle of poverty. 
Table 3. Age, gender and year of study adjusted linear regression models for determinants of absolute BP levels*

\begin{tabular}{|c|c|c|c|c|c|c|c|c|}
\hline & \multicolumn{4}{|c|}{ Model 1: SBP } & \multicolumn{4}{|c|}{ Model 2: DBP } \\
\hline & \multirow[b]{2}{*}{$\beta$} & \multicolumn{2}{|c|}{$95 \% \mathrm{CI}$} & \multirow[b]{2}{*}{$p$-value } & \multirow[b]{2}{*}{$\beta$} & \multicolumn{2}{|c|}{$95 \% \mathrm{CI}$} & \multirow[b]{2}{*}{$p$-value } \\
\hline & & Lower limit & Upper limit & & & Lower limit & Upper limit & \\
\hline Year of study & 15.6 & 13.9 & 17.4 & $<0.001$ & 11.1 & 10.0 & 12.2 & $<0.001$ \\
\hline Gender (male) & 1.1 & -0.7 & 3.0 & 0.233 & -0.8 & -2.0 & 0.4 & 0.180 \\
\hline Age (per 5 years) & 3.3 & 3.1 & 3.6 & $<0.001$ & 0.8 & 0.6 & 1.0 & $<0.001$ \\
\hline BMI & 0.4 & 0.3 & 0.6 & $<0.001$ & 0.4 & 0.3 & 0.5 & $<0.001$ \\
\hline Waist circumference & 0.2 & 0.2 & 0.3 & $<0.001$ & 0.2 & 0.2 & 0.2 & $<0.001$ \\
\hline Diabetes & 6.1 & 4.0 & 8.2 & $<0.001$ & 2.3 & 0.9 & 3.6 & $<0.001$ \\
\hline Prediabetes & 4.4 & 2.1 & 6.6 & $<0.001$ & 2.4 & 0.9 & 3.8 & $<0.001$ \\
\hline Current smoking & -1.9 & -3.6 & -0.2 & 0.029 & -1.6 & -2.7 & -0.6 & $<0.001$ \\
\hline $\begin{array}{l}\text { Secondary level of education } \\
\text { or higher }\end{array}$ & -2.3 & -4.1 & -0.5 & 0.012 & -1.0 & -2.2 & 0.1 & 0.090 \\
\hline Current drinking & 3.0 & 1.0 & 5.0 & 0.003 & 2.5 & 1.2 & 3.7 & $<0.001$ \\
\hline Past drinking & -2.2 & -4.6 & 0.2 & 0.081 & -0.6 & -2.2 & 0.9 & 0.420 \\
\hline
\end{tabular}

Table 4. Age, gender and year of study adjusted multivariate linear regression models for determinants of absolute BP levels

\begin{tabular}{|c|c|c|c|c|c|c|c|c|}
\hline & \multicolumn{4}{|c|}{ Model 1: SBP } & \multicolumn{4}{|c|}{ Model 2: DBP } \\
\hline & \multirow[b]{2}{*}{$\beta$} & \multicolumn{2}{|c|}{$95 \% \mathrm{CI}$} & \multirow[b]{2}{*}{$p$-value } & \multirow[b]{2}{*}{$\beta$} & \multicolumn{2}{|c|}{$95 \% \mathrm{CI}$} & \multirow[b]{2}{*}{$p$-value } \\
\hline & & Lower limit & Upper limit & & & Lower limit & Upper limit & \\
\hline Year of study & 16.0 & 14.2 & 17.7 & $<0.001$ & 11.8 & 10.7 & 12.9 & $<0.001$ \\
\hline Gender (male) & 3.5 & 1.5 & 5.4 & 0.001 & 0.6 & -0.7 & 1.8 & 0.37 \\
\hline Age (per 5 years) & 2.9 & 2.6 & 3.2 & $<0.001$ & 0.7 & 0.5 & 0.9 & $<0.001$ \\
\hline BMI & 0.4 & 0.3 & 0.6 & $<0.001$ & 0.2 & 0.1 & 0.3 & $<0.001$ \\
\hline Diabetes & 4.9 & 2.8 & 7.0 & $<0.001$ & & & & \\
\hline Prediabetes & 3.1 & 0.9 & 5.4 & 0.006 & & & & \\
\hline $\begin{array}{l}\text { Secondary level of education } \\
\text { or higher }\end{array}$ & -2.3 & -3.8 & -0.8 & 0.003 & & & & \\
\hline Current drinking & 3.0 & 1.0 & 5.0 & 0.003 & 3.5 & 2.3 & 4.7 & $<0.001$ \\
\hline
\end{tabular}

Similar findings have been reported in developing countries such as China and India. Wang et al. ${ }^{[19]}$ reported an increase in hypertension prevalence in China between 1991 and 2011, with the greatest rise (68\%) in females aged 35 - 44 years. Similarly, Roy et al.$^{[20]}$ reported that the highest prevalence of change between 1991 and 2012 in India was in the age group 35 - 44 years. However, these findings contrast with reports in general, where the increase in hypertension has been reported as mostly due to 'an ageing world population,, ${ }^{[16]}$ with longer life expectancy resulting in increased exposure to risk factors. ${ }^{[16]}$ It is unclear from the results of the present study why there was a shift in the peak prevalence of hypertension to middle age, but it may have been due to changes in lifestyle and/or environmental surroundings, including working environments. With regard to the latter, SA has recently been reclassified as a middle- to high-income country by the World Bank, ${ }^{[21]}$ suggesting that working conditions may be becoming more stressful. However, the increased burden of disease in younger individuals will increase the load on the healthcare system, and more importantly affect the economy because people affected by the disease are in the prime of their working careers. Efforts aimed at screening therefore need to be intensified in this age group. Regular screening for raised BP could be effective in detecting the disease at an early stage and could possibly be used by management dealing with workloads and responsibilities in stressful work environments.

\section{Risk factors associated with hypertension}

The traditional risk factors for hypertension of obesity and alcohol intake were significantly associated with hypertension in this study, highlighting the influence of urbanisation and other environmental factors on the development of the disease. However, smoking was not positively associated with hypertension, similar to findings in black Africans in Cape Town. ${ }^{[3]}$

The association of diabetes with hypertension was unsurprising. It underscores the frequent coexistence of these diseases and that, if one is present, the other should be screened for. Lifestyle and cultural norm changes such as decreased physical activity are well known aspects of modern working environments. Similarly, changes in traditional habits of males and females, such as the increase in smoking and drinking among females (and the increase in smoking among males) in the 2014/16 study population, are major factors that fuel the NCD epidemic in developing countries. ${ }^{[22,23]}$

Results from the present study showed alcohol consumption to be positively and smoking inversely associated with BP (both SBP and DBP), but the association with smoking became non-significant after using backward selection in a multivariate selection model, However, the phenomenon of an inverse association between smoking and high BP has also been reported in the 2014 China National Health Survey, where smoking was associated with 


\begin{tabular}{|c|c|c|c|c|}
\hline \multirow[b]{2}{*}{ Variables in each model } & \multicolumn{2}{|c|}{ Overall hypertension $(N=2$ 897) } & \multicolumn{2}{|c|}{ Screen-detected hypertension $(N=1852)$} \\
\hline & OR $(95 \% \mathrm{CI})$ & $p$-value & OR $(95 \% \mathrm{CI})$ & $p$-value \\
\hline Year & & $<0.001$ & & $<0.001$ \\
\hline 2008/09 & 1 & & 1 & \\
\hline $2014 / 16$ & $2.83(2.33-3.45)$ & & $4.33(3.29-5.69)$ & \\
\hline Age (years) & & $<0.001$ & & $<0.001$ \\
\hline $20-29$ & 1 & & 1 & \\
\hline $30-39$ & $2.46(1.62-3.75)$ & & $2.18(1.37-3.48)$ & \\
\hline $40-49$ & $5.65(3.79-8.41)$ & & $4.50(2.89-7.02)$ & \\
\hline $50-59$ & $9.55(6.39-14.27)$ & & $5.36(3.40-8.44)$ & \\
\hline $60-69$ & $18.27(11.84-28.21)$ & & $8.20(4.95-13.60)$ & \\
\hline$\geq 70$ & $26.46(16.31-42.93)$ & & $14.54(8.2-25.80)$ & \\
\hline Gender & & 0.938 & & 0.110 \\
\hline Female & 1 & & 1 & \\
\hline Male & $1.01(0.81-1.26)$ & & $1.24(0.95-1.63)$ & \\
\hline Level of education & & 0.750 & & 0.040 \\
\hline Primary or lower & 1 & & 1 & \\
\hline Secondary or higher & $0.75(0.61-0.91)$ & & $0.77(0.60-0.99)$ & \\
\hline Alcohol use & & $<0.001$ & & $<0.001$ \\
\hline Non-drinker & 1 & & 1 & \\
\hline Current drinker & $1.56(1.24-1.96)$ & & $1.81(1.38-2.38)$ & \\
\hline Past drinker & $0.94(0.72-1.23)$ & & $0.58(0.39-0.86)$ & \\
\hline Tobacco use & & 0.870 & & 0.271 \\
\hline Non-smoker & 1 & & 1 & \\
\hline Smoker & $0.87(0.71-1.05)$ & & $0.87(0.68-1.11)$ & \\
\hline BMI category & & $<0.001$ & & $<0.001$ \\
\hline Normal & 1 & & 1 & \\
\hline Overweight & $1.52(1.19-1.94)$ & & $1.45(1.07-1.96)$ & \\
\hline Obese & $2.56(2.02-3.24)$ & & $2.11(1.57-2.84)$ & \\
\hline Diabetic status & & $<0.001$ & & 0.249 \\
\hline Normal & 1 & & 1 & \\
\hline Prediabetic & $1.17(0.92-1.49)$ & & $0.98(0.72-1.34)$ & \\
\hline Diabetic & $2.40(1.88-3.07)$ & & $1.31(0.94-1.82)$ & \\
\hline
\end{tabular}

lower BP, while cessation of smoking was linked to increased hypertension. ${ }^{[16,24]}$

\section{Study strengths and limitations}

The strength of this study is that the two surveys were conducted in the population from the same geographical area, using similar procedures. However, the study has the following limitations: (i) it consisted of only two cross-sectional surveys, which prevented reliable assessment of trends; (ii) the second study was not a follow-up but rather another cross-sectional study collecting new participants from the area; (iii) there was a low proportion of men in the two studies (24\%), a common problem in SA research; ${ }^{[3]}$ (iv) there was no information on high salt intake, which is known to contribute to the development of hypertension; $(v)$ although information on hypertension treatment was obtained from participants, control was not evaluated; and $(v i)$ hypertension target organ damage was not assessed. The latter precluded the evaluation of hypertension control and optimal management across the two surveys.

\section{Conclusions}

Our findings have shown a rightward shift in absolute BP in the SA mixed-ancestry population that translated into a significant increase in the prevalence of hypertension, particularly screen-detected cases, in both males and females over a 7 -year period. The traditional risk factors for hypertension of obesity, diabetes and alcohol intake were significantly associated with hypertension in this study, highlighting the influence of urbanisation and other environmental factors on the development of the disease.

A concerted drive on the part of the healthcare sector to increase awareness of hypertension and BP status in this population group is of crucial importance. The severity of hypertension-related complications and the minimal costs involved in measuring $\mathrm{BP}$ necessitate screening on a much wider scale than is the case at present, possibly in the workplace as well as in the healthcare environment, to manage and prevent the cardiovascular diseases that result from hypertension.

Declaration. This study formed part of SFGD's PhD degree.

Acknowledgements. We thank the Bellville South (Ward 9) community for their participation in 2008/09 and 2014/16 and their community health forum for supporting the present study.

Author contributions. SFGD: drafting of the article, statistical analysis, interpretation of data and writing the discussion. TEM: conceptualisation, 
and took part in the analysis and interpretation of the data, writing the discussion and proofreading and correcting the article. NP: approved the concept, commented on the interpretation of data and the discussion, and took part in proofreading and correcting the article. RTE: commented on and amended all aspects of the article, i.e. background, methods and discussion. APK: conceptualisation, took part in the analysis and interpretation of the data and the discussion, helped proofread and correct the article, and gave final approval of the article. All the authors read and approved the final manuscript.

Funding. This research project was supported by a grant from the University Research Fund of the Cape Peninsula University of Technology and the South African Medical Research Council (MRC), with funds from National Treasury under its Economic Competitiveness and Support Package (MRC-RFA-UFSP-01-2013/VMH Study). Any opinions, findings, conclusions or recommendations expressed in this article are those of the author(s), and the MRC does not accept any liability in this regard.

Conflicts of interest. None.

1. World Health Organization. A Global Brief on Hypertension: World Health Day 2013. Geneva WHO, 2013. https://www.who.int/cardiovascular_diseases/publications/global_brief_hypertension/ en/ (accessed 21 May 2019).

2. Ataklte F, Erqou S, Kaptoge S, et al. Burden of undiagnosed hypertension in sub-Saharan Africa: A systematic review and meta-analysis. Hypertension 2015;65(2):291-298. https://doi.org/10.1161/ A systematic review and meta-anal

3. Peer N, Steyn K, Lombard C, Gwebushe N, Levitt N. A high burden of hypertension in the urban black population of Cape Town: The Cardiovascular Risk in Black South Africans (CRIBSA) study. PLoS One 2013;8(11):e78567. https://doi.org/10.1371/journal.pone.0078567

4. Ibrahim MM, Damasceno A. Hypertension in developing countries. Lancet 2012;380(9841):611-619. https://doi.org/10.1016/S0140-6736(12)60861-7

5. National Department of Health, South Africa, South African Medical Research Council and DHS Program, USA. South Africa Demographic and Health Survey 2016: Key Indicators Report. Pretoria: Statistics South Africa, 2017. https://www.statssa.gov.za/publications/Report\%2003-00-09/Report\%20 03-00-092016.pdf (accessed 20 May 2019).

6. National Department of Health, South Africa. South Africa Demographic and Health Survey 1998. https://www.dhsprogram.com/pubs/pdf/FR131/FR131.pdf (accessed 21 May 2019).

7. Statistics South Africa. Mid-year population estimates July 2017. Statistical release P0302. Pretoria: Statistics South Africa. Mid-year population estimates July 2017. Statistical release P0302. Pretoria:
Stats SA, 2017. https://www.statssa.gov.za/publications/P0302/P03022017.pdf (accessed 21 May 2019). Stats SA, 2017. https://www.statssa.gov.za/publications/P0302/P03022017.pdf (accessed 21 May 2019).
8. De Wit E, Delport W, Rugamika CE, et al. Genome-wide analysis of the structure of the South African 8. De Wit E, Delport W, Rugamika CE, et al. Genome-wide analysis of the structure of the South African
coloured population in the Western Cape. Hum Genet 2010;128(2):145-153. https://doi.org/10.1007/ coloured population
s00439-010-0836-1
9. Zemlin AE, Matsha TE, Hassan MS, Erasmus RT. HbAlc of $6.5 \%$ to diagnose diabetes mellitus Does it work for us? - The Bellville South Africa Study. PLoS One 2011;6(8):e22558. https://doi. org/10.1371/journal.pone.0022558

10. World Health Organization. The WHO STEPS Surveillance Manual. Geneva: WHO, 2012. https:// apps.who.int/iris/bitstream/handle/10665/43376/9241593830_eng.pdf?sequence=1 \&isAllowed=y (accessed 22 May 2019)

11. World Health Organization. Definition and Diagnosis of Diabetes Mellitus and Intermediate Hyperglycemia. Geneva: WHO, 2006. https://www.who.int/diabetes/publications/Definition\%20 and\%20diagnosis\%20of\%20diabetes_new.pdf (accessed 22 May 2019).

12. Benowitz NL. The use of biologic fluid samples in assessing tobacco smoke consumption. Natl Inst Drug Abuse Res Monogr 1983;48:6-26. https://www.researchgate.net/profile/John_Grabowski/ publication/16753447_Issues_in_the measurement_of_smoking_summary_and_discussion/ links/563245a308ae584878091b89/Issues-in-the-measurement-of-smoking-summary-anddiscussion.pdf\#page=17 (accessed 4 June 2019).

13. Caraballo R, Giovino G, Pechacek T. Self-reported cigarette smoking vs. serum cotinine among U.S. adolescents. Nicotine Tob Res 2004;6(1):19-25. https://doi.org/10.1080/14622200310001656821

14. Statistics South Africa. Statistical release (Revised): Census 2011. P0301.4. Pretoria: Stats SA, 2012. https://www.statssa.gov.za/publications/P03014/P030142011.pdf (accessed 22 May 2019).

15. National Department of Health, South Africa. Strategic Plan for the Prevention and Control of Noncommunicable Diseases 2013 - 17. RP06/2013. http://www.hsrc.ac.za/uploads/pageContent/3893/ NCDs\%20STRAT\%20PLAN\%20\%20CONTENT\%208\%20april\%20proof.pdf (accessed 22 May 2019).

16. Olsen MH, Angell SY, Asma S, et al. A call to action and a life course strategy to address the global burden of raised blood pressure on current and future generations: The Lancet Commission on Hypertension. Lancet 2016;388(10060):2665-2712. https://doi.org/10.1016/S0140-6736(16)31134-5

17. Western Cape Government. 2016 Socio-economic Profile: City of Cape Town. 2016. https://www. westerncape.gov.za/assets/departments/treasury/Documents/Socio-economic-profiles/2016/Cityof-Cape-Town/city_of_cape_town_2016_socio-economic_profile_sep-lg.pdf (accessed 8 February 2018).

18. Western Cape Government Provincial Treasury. Regional Development Profile: City of Cape Town: Working paper. 2012. https://www.westerncape.gov.za/assets/departments/treasury/dc0_city_of_ cape_town_sep-lg_profile_02_2013.pdf (accessed 22 May 2019).

19. Wang J, Ning X, Yang L, et al. Trends of hypertension prevalence, awareness, treatment and control in rural areas of northern China during 1991 - 2011. J Hum Hypertens 2014;28(1):25-31. https:// doi.org/10.1038/jhh. 2013.44

20. Roy A, Praveen PA, Amarchand R, et al. Changes in hypertension prevalence, awareness, treatment and control rates over 20 years in National Capital Region of India: Results from a repeat crosssectional study. BMJ Open 2017;7(7):e015639. https://doi.org/10.1136/bmjopen-2016-015639

21. Fantom NJ, Serajuddin U. The World Bank's Classification of Countries by Income (English), Policy Research Working Paper No. WPS 7528. Washington, DC: World Bank Group, 2016. http:// Pocuments.worldbank.org/curated/en/408581467988942234/The-World-Banks-classification-ofcountries-by-income (accessed 22 May 2019).

22. Addo J, Smeeth L, Leon DA. Hypertension in sub-Saharan Africa: A systematic review. Hypertension 2007;50(6):1012-1018. https://doi.org/10.1161/HYPERTENSIONAHA.107.093336

23. Hancock C, Kingo L, Raynaud O. The private sector, international development and NCDs. Global Health 2011;7:23. https://doi.org/10.1186/1744-8603-7-23

24. Li G, Wang $\mathrm{H}$, Wang $\mathrm{K}$, et al. The association between smoking and blood pressure in men: $\mathrm{A}$ crosssectional study. BMC Public Health 2017;17(1):1-6. https://doi.org/10.1186/s12889-017-4802-x

Accepted 13 December 2018 